City University of New York (CUNY)

CUNY Academic Works

\title{
The Effects of Merging Proactive CCTV Monitoring with Directed Police Patrol: A Randomized Controlled Trial.
}

Eric L. Piza

CUNY John Jay College of Criminal Justice

Joel M. Caplan

School of Criminal Justice, Rutgers University

Leslie W. Kennedy

School of Criminal Justice, Rutgers University

Andrew M. Gilchrist

School of Criminal Justice, University of Cincinnati

\section{How does access to this work benefit you? Let us know!}

More information about this work at: https://academicworks.cuny.edu/jj_pubs/175

Discover additional works at: https://academicworks.cuny.edu

This work is made publicly available by the City University of New York (CUNY).

Contact: AcademicWorks@cuny.edu 


\title{
The effects of merging proactive CCTV monitoring with directed police patrol: a randomized controlled trial
}

\author{
Eric L. Piza • Joel M. Caplan • Leslie W. Kennedy • \\ Andrew M. Gilchrist
}

Published online: 15 July 2014

(C) Springer Science+Business Media Dordrecht 2014

\begin{abstract}
Objectives This study was designed to test the effect of increased certainty of punishment on reported crime levels in CCTV target areas of Newark, NJ. The experimental strategy was designed for the purpose of overcoming specific surveillance barriers that minimize the effectiveness of CCTV, namely high camera-to-operator ratios and the differential response policy of police dispatch. An additional camera operator was deployed to monitor specific CCTV cameras, with two patrol cars dedicated to exclusively responding to incidents of concern detected on the experimental cameras. Methods A randomized controlled trial was implemented in the analysis. A randomized block design was used to assign each of the 38 CCTV schemes to either a treatment or control group. Schemes were grouped into pairs based upon their levels of three types of calls for service: violent crime, social disorder, and narcotics activity. Negative binomial regression models tested the effect that assignment to the treatment group had on levels of the aforementioned crime categories.

Results The experimental strategy was associated with significant reductions of violent crime and social disorder in the treatment areas relative to the control areas. Incidence Rate Ratio (IRR) and Total Net Effect (TNE) values suggest that the number of crime incidents prevented was sizable in numerous instances. The experiment had much less of an effect on narcotics activity.

Conclusions Overall, the findings support the hypothesis that the integration of CCTV with proactive police activity generates a crime control benefit greater than what
\end{abstract}

Electronic supplementary material The online version of this article (doi:10.1007/s11292-014-9211-x) contains supplementary material, which is available to authorized users.

\section{E. L. Piza $(\bowtie)$}

Department of Law and Police Science, John Jay College of Criminal Justice, 524 West 59th St., Haaran Hall, Room 422.14T, New York, NY 100109, USA

e-mail: epiza@jjay.cuny.edu

School of Criminal Justice, Rutgers University, Newark, NJ, USA 
research suggests is achievable via "stand-alone" camera deployment, particularly in the case of street-level crime.

Keywords CCTV Crime prevention $\cdot$ Randomized block design $\cdot$ Randomized field experiment $\cdot$ Video surveillance $\cdot$ Viewsheds

\section{Introduction}

"When the type of stuff that they're (offenders) involved in kept happening and they realized they weren't getting arrested, nothing was happening because of those cameras. I do not think (the camera program) works as a deterrent at all....because there's no immediate consequence to the behavior" (King et al. 2008: p. 86-87). The previous quote was provided by a San Francisco police inspector during an interview with researchers from the University of California, Berkeley. This quote articulates an inherent shortcoming of CCTV use by police, namely that the practical application of CCTV typically results in surveillance barriers that hinder the occurrence of enforcement activity (Piza et al. 2012). Such low levels of enforcement may diminish CCTV's crime prevention capacity, since certainty of punishment is widely recognized as a key aspect of deterrence (Durlauf and Nagin 2011). As articulated by Pease (1999) "No public place...will be crime free if offenders have good reason to believe that they will not be recognised, or, if recognised, will not be reported to the police, or, if reported will escape meaningful criminal justice outcomes" (p. 49). Therefore, the increased risk suggested by camera presence can ring hollow if offenders learn that CCTV does not truly increase the likelihood of apprehension in response to crime commission (Tilley 1993).

The current study reports the results of a randomized controlled trial testing the effect of increasing certainty of punishment on the crime prevention capacity of CCTV in Newark, NJ. The experimental strategy was designed for the purpose of overcoming specific surveillance barriers that prior research has found to impede upon the certainty of punishment in CCTV systems: high camera-to-operator ratios and the differential response strategy of police dispatch. Results suggest that the experiment increased proactive CCTV activity while producing a significant reduction of violent crime and social disorder incidents. The experiment did not have a significant effect on narcotics activity. These findings have implications for policeled CCTV strategies. Specifically, this study supports the hypothesis that the integration of CCTV with proactive, focused police activity generates crime control benefits greater than what research suggests is achievable via stand-alone camera deployment.

\section{Review of relevant literature}

CCTV and crime prevention

Champions of video surveillance have consistently touted the technology as an effective crime deterrent and a force multiplier for the police (Norris 2003). Such enthusiasm 
has led many to view CCTV as a panacea against crime, an "all seeing" mechanism that is successful in all circumstances (Fyfe and Bannister 1996). Norris and Armstrong (1999a) argued that this widespread acceptance of CCTV is largely the result of "technological determinism," which they define as "an unquestioning belief in the power of technology" (p. 9). Whatever the driver, public stakeholders' enthusiasm for CCTV quickly translated into public policy. In Great Britain, for example, the vast expansion of government-funded CCTV systems established CCTV as the "crime prevention initiative of the century" (Norris and Armstrong 1999a) with leaders from both major political parties allocating substantial funds towards CCTV-related projects since the early 1990's (Taylor 2010). This rapid expansion of CCTV has seemingly spread to the United States. While the latest meta-analysis by Welsh and Farrington (2009) identified only one evaluation conducted in the U.S. (Mazerolle et al. 2002), numerous U.S. evaluations have appeared in the relatively short time since the review (Cameron et al. 2008; Caplan et al. 2011; King et al. 2008; La Vigne et al. 2011; McLean et al. 2013; Ratcliffe et al. 2009). Furthermore, published studies likely represent a fraction of the overall systems in the U.S., with news reports suggesting "that CCTV cameras are being implemented at a significant rate" (Ratcliffe et al. 2009: p. 749).

Despite this rapid expansion, evidence of CCTV's effectiveness is inconclusive, at best. Some studies find CCTV to be moderately effective (Armitage et al. 1999; Caplan et al. 2011; Gill and Spriggs 2005; La Vigne et al. 2011; McLean et al. 2013; Ratcliffe et al. 2009) with others finding little-to-no effect (Brown 1995; Cameron et al. 2008; King et al. 2008; Waples and Gill 2006). Meta analyses conducted by Welsh and Farrington (2002, 2007, 2009) suggest that, while CCTV has little effect in most settings, it is effective in preventing motor vehicle crime in car parks. However, in each of the car park evaluations included in the meta-analyses, CCTV was combined with other interventions, namely improved lighting, improved fencing, and security guards. Furthermore, a more recent evaluation of a car park system (Reid and Andresen 2014) found no evidence (via monthly structural break tests) that CCTV influenced crime levels. Interestingly, Reid and Andresen (2014) found that an alternate 1-year pre/ post test indicated a significant drop in vehicle crime. Thus, evidence in-support of car park systems may speak more to the impact of a package of interventions (Welsh and Farrington 2007: p. 47) or the choice of statistical models (Reid and Andresen 2014) than CCTV effect, adding to the inconclusiveness of the literature.

\section{CCTV and deterrence mechanisms}

Such inconclusive findings have led some to conclude that CCTV has not lived up to its initial lofty expectations (Sasse 2010). Recent research suggests that the shortcomings of CCTV may be largely related to the detached manner in which it is incorporated into police operations. CCTV systems often have a vague mission to "prevent crime," with little consideration given to a number of pertinent issues, namely best practices regarding camera monitoring and police response (Gill and Spriggs 2005; Piza et al. 2012, 2014a, b). This has often led police to deploy CCTV as a stand-alone mechanism rather than integrating surveillance into existing practices of the agency (La Vigne et al. 2011).

The theoretical underpinnings of CCTV suggest that the mere presence of cameras may be insufficient to generate significant crime reductions. CCTV is considered a 
situational crime prevention measure that specifically aims to reduce crime by increasing the perceived risks to potential offenders (Clarke 1997: p. 18). However, little attention has been paid to exactly how CCTV can increase perceived risks. On the one hand, camera presence alone may seem adequate to communicate an increased level of risk within a target area. Indeed, a widely accepted proposition is "CCTV will be most effective if potential offenders believe that they will be seen" (Farrington et al. 2007: p. 22). This suggests a deterrence mechanism by which an offender recognizes a camera, considers the risk of offending to outweigh the potential rewards, and chooses to abstain in this instance. This risk-calculus aligns with the Rational Choice Theory (Cornish and Clarke 1986), which argues that offender decision making involves a number of "choice structuring properties" comprising the pros, cons, and inherent risk involved in the commission of a particular crime.

In the study of CCTV, the influence of camera presence on offender decision making has seemingly been taken for granted by researchers. As noted by Mazerolle et al. (2002), "for some people, the very presence of CCTV is enough to deter" (p. 59). However, offender behavior suggests that such calculations are not always as we would expect. Numerous studies have documented offender willingness to operate in sight of surveillance cameras (Butler 1994; Ditton and Short 1998; Gill and Loveday 2003; Gill and Turbin 1998). During interviews with prisoners, Gill and Loveday (2003) found that most offenders did not consider CCTV as a serious threat. Interestingly, offenders were more concerned with police presence and the ability of the police to respond to crime observed on camera than the cameras themselves. Indeed, while Gill and Loveday (2003) found that most offenders did not equate CCTV with increased risk of punishment, those previously caught or convicted through surveillance footage were significantly more likely to report that CCTV increases the likelihood of apprehension.

The findings of Gill and Loveday (2003) suggest that CCTV operations may need to incorporate more than conspicuous camera presence in order to produce deterrence. Recent research further suggests that CCTV effect may be bolstered when the technology is integrated into proactive police strategies, rather than deployed as a stand-alone tactic. In their study of CCTV in three U.S. cities, La Vigne et al. (2011) found the systems that effectively reduced crime were those incorporating active monitoring of cameras and direct integration of CCTV into proactive police functions. Conversely, the systems removed from active monitoring and proactive police activities produced no tangible crime control benefits. However, CCTV integration into the police function was ascertained from discussions with police personnel rather than any empirical measures. Thus, the precise relationship between proactive enforcement and CCTV effect remains somewhat elusive.

Despite the imprecise evidence regarding the influence of proactive enforcement on CCTV effect, findings from the policing literature provide additional support for the hypothesis that integration with proactive police activity may enhance CCTV operations. Decades of research confirm that the standard model of policing, comprised of mainly reactive strategies, has little crime control utility, with highly focused, proactive police practices having a strong track record of crime reduction (Lum et al. 2011; Skogan and Frydl 2004; Weisburd and Eck 2004). The finding regarding the effect of focused, proactive policing has largely been attributed to police strategies, such as hot spots policing and problem-oriented policing. However, evidence suggests that 
particular police actions, which can be incorporated into a wide-range of strategies, can also generate significant crime reductions. For example, in their review of research on policing Sherman and Eck (2002) found that proactive arrests (generated through officer-initiated activity, rather than a citizen call-for-service) effectively reduced crime across a wide range of studies and research designs. In explaining this finding, Sherman and Eck (2002) hypothesized that proactive arrests strategically applied towards problematic places or offenders create higher certainty of punishment than generally applied reactive police enforcement. This implies that maximizing proactive police enforcement in CCTV operations, where officers swiftly address incidents detected and reported by CCTV operators (rather than 9-1-1 calls), may be promising.

CCTV's detachment from proactive policing: the effect of surveillance barriers

Unfortunately, the practical application of CCTV typically results in the emergence of surveillance barriers that impede upon proactive surveillance functions (Piza et al. 2012). The first surveillance barrier relates to how CCTV is typically incorporated into the police function. Despite being a technological innovation, CCTV is deployed in a manner that ties it to reactive law enforcement philosophies originating from the Professional Era of policing, specifically regarding police deployment (Wilson 1963). Specifically, both CCTV detections and 9-1-1 calls are typically reported via the computer-aided dispatch (CAD) system and addressed in a differential response manner, with calls of a higher priority being dispatched before lower priority calls (LEITSC 2008). This process negates any benefits offered by CCTV's real-time discovery of crime or its precursors. In addition, the differential response nature of dispatch may discourage CCTV operators from reporting incidents they detect on camera. Operators may become frustrated when CCTV detections do not receive a timely police response and may, as a result, not bother reporting certain incidents. For example, Lomell (2004) reported that CCTV operators in Oslo, Norway stopped reporting street-level drug transactions due to the police emphasizing the apprehension of drug traffickers rather than the disruption of street-level markets. Similarly, Norris and McCahill (2006) documented a CCTV operator not reporting in-progress shoplifting due to his belief that there was not enough staff on duty for a swift response.

The second common surveillance barrier relates to the large number of cameras typically present within CCTV systems. For example, Norris and Armstrong (1999a: p. 159) estimated that the 20 cameras in a British CCTV system created over 43 million unique "images" on a daily basis, presenting operators with an unrealistic amount of footage to monitor. This burden is compounded when systems include a large amount of cameras, which appears to be the norm (Farrington et al. 2007). Research in the cognitive and behavioral sciences has found that humans work with a limited capacity of visual memory (Cowan 2000; Luck and Vogel 1997), and the accuracy and speed of task completion drastically reduces as task complexity increases (Halford et al. 2005). While empirically determining the complexity of CCTV monitoring is difficult, previous research has found that operators believe they cannot adequately monitor the number of cameras within their respective systems (Keval and Sasse 2010). Indeed, Piza et al. (2012) found an inverse, significant relationship between CCTV system size and CCTV activity, with other research generating similar results (Gill et al. 2005). 
Literature review summary and scope of the current study

Surveillance barriers seem to have a minimizing effect on the active monitoring of CCTV, with research reporting proactive activity to be a rare occurrence. This finding is consistent across a range of metrics, such as detection of crime by CCTV operators (Gill and Hemming 2004; Piza et al. 2012), arrests and other enforcement actions generated by CCTV (Ditton and Short 1999; Piza et al. 2012), the capturing of visual evidence for prosecution (King et al. 2008; Sarno et al. 1999), and targeted surveillances: observations of an individual or group lasting one minute or more (Norris and Armstrong 1999a, b; Norris and McCahill 2006). The lack of enforcement likely means that "the certainty of a disciplinary response to deviancy is absent" in CCTV operations (Norris and Armstrong 1999b: p. 199). With certainty of punishment being a key aspect of deterrence (Durlauf and Nagin 2011), the lack of enforcement may minimize CCTV's crime prevention capacity. As argued by Tilley (1993), "If the mechanism is deterrence via a rise in perceived risk which is not rooted in real risk increase, then many offenders may come to appreciate that they can safely resume their criminal behavior" (p. 5).

In an attempt to shed empirical light on these issues, this study reports on a randomized controlled trial conducted in partnership with the Newark, NJ Police Department. The experimental strategy directly addressed the aforementioned surveillance barriers: the high camera-to-operator ratio and the differential response strategy of police dispatch. To alleviate the high camera-to-operator ratio, an additional CCTV operator was deployed to the control room and dedicated to strictly monitoring the treatment areas during the experiment tours-of-duty. To alleviate issues caused by differential police response, the experimental operators were assigned two patrol cars for the purpose of responding to the incidents detected on treatment cameras. Incidents were not reported via $\mathrm{CAD}$, but were relayed via two-way radio directly to the field supervisor patrolling with the experimental police units. The analysis was driven by the research question "What effect did the experimental strategy have on observed crime levels?"

\section{Study setting}

Newark is the largest city in New Jersey, spanning over 26 square miles with a population of 277,140 (U.S. Census Bureau 2010). The city has a long-standing reputation as a tumultuous, dangerous urban environment and has particularly struggled with issues of serious violence (Tuttle 2009). In recent years, the city upgraded many of its technological capabilities, including the installation of a CCTV system in 2007. One-hundred-forty-six surveillance cameras are located throughout Newark to-date. Two CCTV operators under the supervision of a police sergeant monitor live video footage from the cameras during all shifts within a control room at the department's communications center. They are tasked with detecting incidents of probable cause or reasonable suspicion and reporting said incidents via the department's CAD system. Reported incidents (both CCTV detections and calls for service) are stored in CAD's calls-pending queue and addressed in a differential response manner. This process parallels those observed by researchers elsewhere (Gill et al. 2005; Lomell 2004; Ratcliffe et al. 2009). Previous research on Newark's CCTV system shows that it 
suffers from specific shortcomings common to CCTV operations. For one, the system has demonstrated little effect outside the single crime of auto theft. In their analysis of the first 73 cameras installed in Newark, Caplan et al. (2011) found that auto theft was the only one of three crimes included in the analysis to have experienced a statistically significant reduction. Subsequent studies found that Newark's system generated little proactive activity. While the system reported an average of 26.84 detections and 9.47 enforcement actions over its first 19 weeks, a weekly average of only 2.11 detections and 1.22 enforcement actions occurred after the system expanded to 146 cameras (Piza et al. 2012: p. 19). Intra-system statistics further reflect that proactive activity was virtually absent at most camera sites. During their first year in place, $17.9 \%$ of Newark's CCTV cameras generated no detections and $73.5 \%$ generated five detections or less; $55.5 \%$ of cameras generated no enforcement actions and $92.3 \%$ generated five or less (Piza et al. 2014a: p. 242). This lack of activity is likely due to the aforementioned surveillance barriers discussed in the literature review. Piza et al. (2012) found that each additional phase of camera deployment was associated with between a 36 and $47 \%$ reduction in weekly detection levels and between a 39 and $47 \%$ reduction in weekly enforcement levels. While this suggests that the increasing system size was largely responsible for low levels of activity, the differential response policy of police dispatch likely also played a role. During interviews with researchers (Piza et al. 2014b), Newark's CCTV operators reported that they routinely did not report incidents of concern they witnessed on camera because of large calls-pending queue times. For example, when asked why she did not report a particular incident, an operator stated, "Because by the time the radio car gets there they'll be long gone" (p. 12). In all, operators in the Piza et al. (2014b) study "overwhelmingly reported that aspects of police dispatch - specifically large queue times - discouraged them from reporting" many of the criminal infractions they observed (p. 12). If proactive enforcement is truly related to CCTV's deterrent effects, this prior research may explain the lack of a significant, wide spread effect in Newark.

\section{The experimental strategy}

The experiment was designed in a manner that the research team and Newark Police officials believed would improve upon the standard CCTV operation in Newark. The lead author worked with the department's Command Staff to design and implement the intervention. ${ }^{1}$ An additional CCTV operator was deployed to the control room and dedicated to strictly monitoring the treatment areas during the experiment tours-of-duty. We anticipated that having a camera-to-operator ratio drastically lower than that of the

\footnotetext{
${ }^{1}$ We recognize the debate regarding researcher involvement in the design and implementation of interventions. Some scholars have argued that close working relationships between practitioners and academics may create a conflict of interest, which can threaten the validity of the analysis (Eisner 2009). Others have argued that such collaboration is necessary in order to develop, test, and disseminate evidence-based practices (Braga 2010; Olds 2009). While the debate is ongoing, a meta-analysis of experimental and quasi-experimental evaluations of police interventions by Welsh et al. (2012) found no evidence that evaluator involvement in program implementation biased the results. Furthermore, the recent study of Telep et al. (2012) focused on a field experiment carried out primarily by the Sacramento Police Department, adding further support for researcher/practitioner relationships.
} 
normal CCTV operation (73:1) would result in increased levels of CCTV detections. In addition, the experimental operators were assigned two patrol cars for the purpose of responding to the incidents detected on treatment cameras. Incidents were not reported through $\mathrm{CAD}$, but were relayed via two-way radio directly to the field supervisor patrolling with the experimental police units. The field units were exclusively assigned to the experiment. They had no responsibilities for responding to calls-for-service and were instructed not to enact enforcement actions against incidents not reported by the operators (unless they observed or were flagged-down for an in-progress crime or other emergency). We anticipated that the removal of differential response deployment, via the persistent availability of the field units, would result in increased enforcement actions in response to CCTV detections. Control group cameras were monitored and policed as normal, with two operators monitoring all non-experimental cameras and reporting incidents of concern through CAD.

Specific steps were taken to minimize potential threats to validity. For one, if experimental operators were able to watch control cameras, and standard CCTV operators were able to watch experimental cameras, their respective practices could influence one another. To protect against this, the CCTV software was configured so that experimental operators (identified by their username and password) were only able to view experimental cameras during the times of the experiment. Conversely, operators normally assigned to the surveillance unit (likewise identified by their username and password) were only able to monitor non-experiment cameras during the times of the experiment. The experiment's patrol function also raised potential threats to validity. Deploying additional units to target areas may have added to the police presence provided by regular patrol units. Furthermore, experimental units could potentially linger around specific camera locations leading to near-instantaneous response times. In recognition of these threats, officers drove unmarked police cars so as to not increase perceived levels of police presence. Also, when not en-route to a CCTV-detected incident, each unit patrolled a pre-determined grid encompassing all of the experimental cameras. ${ }^{2}$ This protocol maintained the validity of the experiment by ensuring that it measured what it was intended to: the impact of merging proactive CCTV monitoring and directed police patrol, not simply the impact of increased police presence.

The experiment ran for an 11-week period from 7/20/11 to 10/1/11. Based on the Newark Police Department's temporal analysis of violent crime, social disorder, and narcotics activity calls-for-service, the experiment tours were designed to run 4 days a week, Wednesday through Saturday, from $8 \mathrm{pm}$ to $12 \mathrm{am}$. This reflected the days and times the targeted crime categories were at their peak occurrence during the prior summer.

\section{Methodology}

Units of analysis

Units of analysis followed the approach of the newly developed viewshed methodology (Caplan et al. 2011; McLean et al. 2013; Ratcliffe et al. 2009). Viewsheds incorporate

\footnotetext{
${ }^{2}$ This grid is the standard deviation ellipse discussed below.
} 
GIS methods to digitize the actual line-of-sight of CCTV cameras, which more accurately reflects camera coverage than traditional units of analysis, such as aggregate geographies (i.e., neighborhoods or police beats) and circular buffers drawn around camera sites. Viewsheds were created in a hands-on manner, similar to the approach of Ratcliffe et al. (2009). Researchers viewed the live feeds of all CCTV cameras in Newark and digitized the viewshed of each site within a GIS. A detailed base map (with layers displaying streets, land parcels, building footprints, and aerial imagery) was incorporated to ensure that the digitized viewsheds accurately reflected the physical landscape. For example, if the viewable area to the southeast of a camera was obstructed by a building, researchers "snapped" the viewshed boundaries to that building in order to accurately reflect the extent of the camera's view. ${ }^{3}$ From a police patrol standpoint, it makes little sense for viewsheds lying directly adjacent to each other to be considered separate entities. For this reason, viewsheds that overlapped or were directly adjacent (less than one-city block) to each other were grouped together into singular CCTV schemes for the experiment. These modifications created 75 separate CCTV schemes from the 146 individual viewsheds.

To allow for a test of displacement and diffusion of benefits (Clarke and Weisburd 1994), catchment zones were created for each of the CCTV schemes. Following the approach of Ratcliffe et al. (2009), catchment zones began as 291-ft buffers around each viewshed, to reflect the median block size in Newark, as measured within a GIS. The buffers were adjusted to take into account local geography and road patterns. While this approach created zones of slightly varying sizes, it reflected the variability of street networks around cameras. As explained by Ratcliffe et al. (2009), “...the use of actual camera viewsheds can mean that a...buffer stretches to just short of a neighboring intersection. In circumstances like this, the addition of an extra $20 \mathrm{ft}$. is sufficient to include the street intersection... and create a buffer that is a more realistic approximation of the likely displacement area" (p. 752). With this in mind, when a buffer was half a block or less from the nearest intersection, the catchment zone was extended to the intersection. Otherwise, the catchment zone was constricted to the buffer.

\section{Target area selection}

Since only two patrol cars were available for the experiment, Newark Police officials did not want to have the units cover such large an area that intervention dosage was overly diluted. Therefore, to obtain an appropriate target area for the intervention, researchers created a standard deviation ellipse for Newark's CCTV schemes. The ellipse represents one standard deviation around the mean center of the schemes, resulting in an area both concise in size and inclusive of a large proportion of the places of interest (Smith and Bruce 2008). ${ }^{4}$ Thirty-eight schemes (encompassing 64 CCTV cameras) fell within the standard deviation ellipse and were selected for inclusion in the experiment.

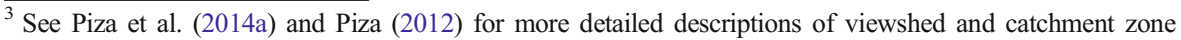
creation.

${ }^{4}$ The ellipse was extended slightly to the northeast so that it encompassed the catchment zones of each scheme.
} 
A randomized block design was used in the creation of treatment and control groups. Randomized block designs minimize the effects of variability between treatment and control groups, allowing for the comparison of equivalent cases (Ariel and Farrington 2010; Weisburd et al. 1993). Randomized block designs have the added benefits of guaranteeing treatment exogeneity and offering transparency for policy makers, since they are generally easier to understand than more technically elaborate research designs (Nagin and Weisburd 2013).

Figure 1 provides a visual flow diagram depicting the progress of the experiment. This outline is in accordance with the Consolidated Standards of Reporting Trials (CONSORT) Statement (www.consort-statement.org). ${ }^{5}$ Founded in the medical field, the CONSORT Statement offers recommendations on the reporting of randomized controlled trials (Schulz et al. 2010). Recently, there has been a push to incorporate the CONSORT Statement into social science research to increase transparency of randomized controlled trials (Grant et al. 2013), fueled by concerns regarding reporting transparency, similar to what was observed in the medical field (Sherman 2010: p. 412).

CCTV Schemes were matched into pairs based on their level of three types of callsfor-service: violent crime, social disorder, and narcotics activity. ${ }^{6}$ These specific crime types were selected for the evaluation in recognition of previous research illustrating CCTV effect to be greatest on automobile crime in car parks and limited in public places, specifically against such street-level activity as the aforementioned crimes. Since we were interested in whether the reconfiguration of Newark's CCTV operation would improve its deterrence capabilities, we tested the strategy's impact on crimes for which CCTV has previously demonstrated limited effect.

Crime levels within each scheme were determined via geoprocessing functions in the ArcGIS software suite. Calls-for-service data were measured for the period July 2010 through September 2010 to mirror the period in 2011 that the Newark Police Department agreed to conduct the experiment. Data were extracted from the Newark Police Department's Records Management System. Calls-for-service data were used rather than Part 1 crime data due to the nature of crime problems under study. Narcotics and disorder incidents are directly reported to police through calls for service, and are not captured within Part 1 crime data. Since calls data were used for these crime types, it made sense to measure violence via the same method to ensure a standard mode of operationalization. $^{7}$

\footnotetext{
${ }^{5}$ The CONSORT Checklist was also used for this report. The checklist provides 25 items that must be included in a Randomized Controlled Trial report to comply with CONSORT standards. We referenced the checklist to ensure that each of the applicable items was presented within this report (see: http://www.consortstatement.org/consort-2010).

${ }^{6}$ Violent crime included the following incident types: assault, carjacking, fight, robbery, shooting (including shots fired), stabbing, and weapons possession. Social disorder included the following incident types: disorderly persons, drinking in public, noise complaint, obstruction of public passage, panhandling, prostitution, and urinating in public. Narcotics activity included the following incident types: Drug activity reported via the anonymous tip line, street-level drug activity, and unverified drug activity (meaning the complainant did not directly witness the drug transaction, but has ample reason to believe a drug transaction occurred).

${ }^{7}$ Calls-for-service may provide advantages over Part 1 crime data since they are less influenced by police discretion (Braga, et al. 1999; Warner and Pierce 1993). However, a potential shortcoming of calls data is they are subject to over reporting due to multiple citizens calling about the same incident (Klinger and Bridges 1997). To protect against this, we deleted duplicate calls-for-service (identified by their police-assigned event numbers) prior to our analysis.
} 


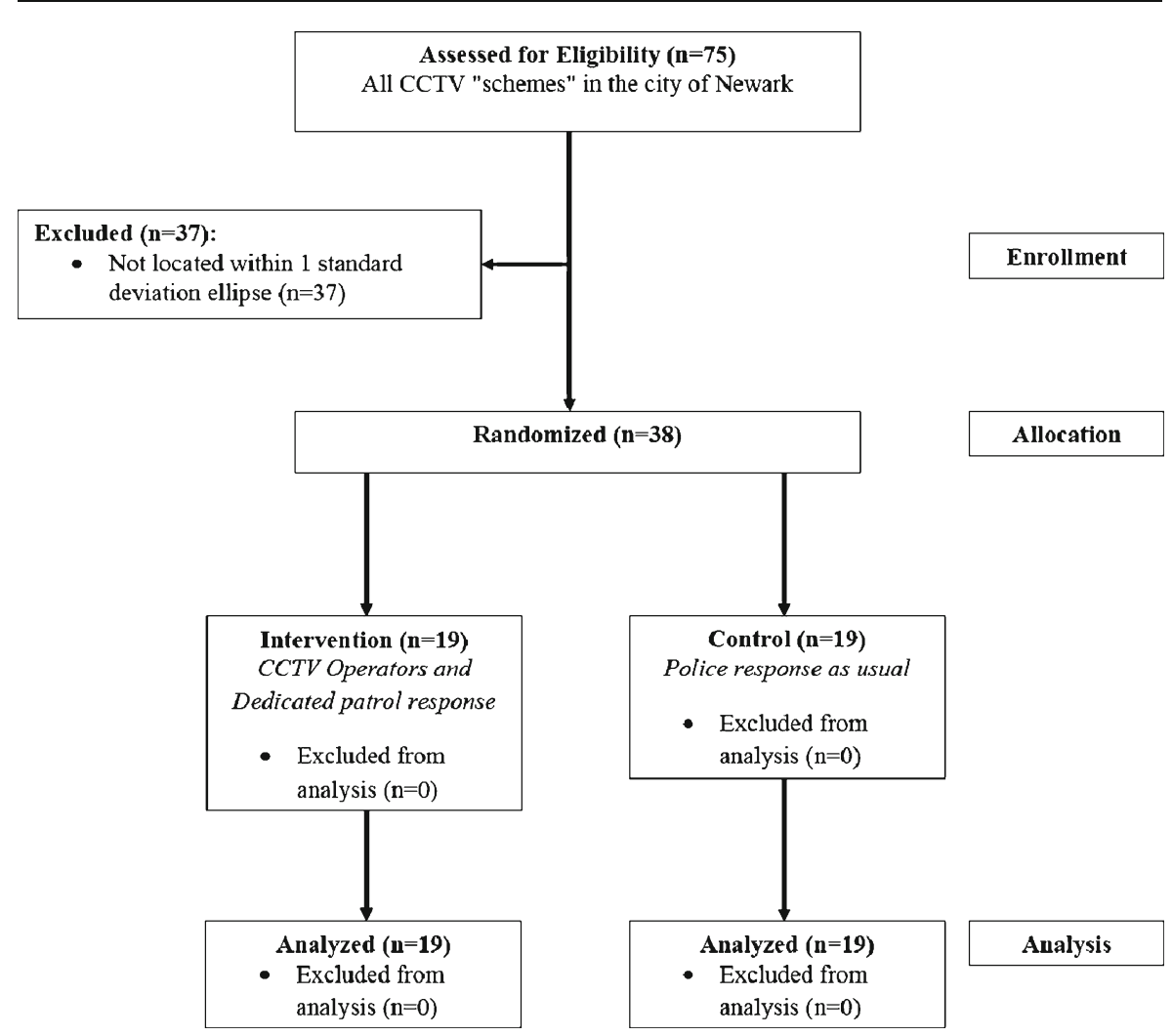

Fig. 1 CONSORT RCT flow diagram of the experiment

Calls-for-service were mapped as point shapefiles and then spatially joined to the CCTV schemes, which generated a count of each crime type for each scheme. CCTV schemes varied in size since they reflected the precise visibility of cameras. Therefore, it is possible that certain schemes may have exhibited higher crime counts than others simply due to their larger area. For this reason, Location Quotients (LQs) were calculated to determine the pairing of schemes. LQs measure the occurrence of crime in a target area compared to its occurrence over a larger control area (Brantingham and Brantingham 1998). LQs were calculated via the following equation: $\mathrm{LQ}=\left(x_{i} / t_{i}\right) /(X / T)$, where $x_{i}$ represents the number of crimes in the scheme $i ; t_{i}$ represents the size of the scheme $i$; and $\mathrm{X}$ and $\mathrm{T}$ represent the numbers of crimes of type $\mathrm{x}$ within a larger control area and the size of the larger area, respectively. ${ }^{8}$

Three separate LQ values were computed for each scheme, to reflect violent crime, social disorder, and narcotics activity. These three LQs were then summed to create a composite value capturing the overall level of crime activity. To reflect the Newark Police Department's desire to emphasize violent crime, the violence LQ was weighted to be more influential than social disorder and narcotics activity in the following

\footnotetext{
${ }^{8}$ The standard deviation ellipse, rather than the entirety of Newark, was considered the control area in the LQ formula. Therefore, the crime count and square footage of the ellipse were used as X and T, respectively, in the denominator of the LQ formula.
} 
formula: Composite $\mathrm{LQ}=($ Violence LQ $* 1.5)+$ Narcotics $L Q+$ Disorder LQ. The schemes were sorted and grouped into 19 different pairs based on their composite LQ values. One case from each pair was then randomly selected (via random numbers generated in Microsoft Excel) to the treatment group with the other being assigned to the control group (see Fig. 2). Paired-samples $t$ tests (across the 19 different pairs of schemes) were conducted to compare the pre-intervention crime levels of the experimental and control schemes, from July through September 2010. For each crime category, the difference between the mean number of incidents in treatment and control areas was insignificant, demonstrating balance between the groups. ${ }^{9}$

\section{Analytical design}

The evaluation is driven by the research question, "What effect did the experimental strategy have on observed crime levels?" The effect of the experimental strategy was tested through a series of negative binomial regression models. ${ }^{10}$ The models were constructed in a manner consistent with prior place-based policing experiments (i.e., Braga and Bond 2008; Braga et al. 1999; Ratcliffe et al. 2011; Taylor et al. 2011). The dependent variable in each model was the number of events occurring during the experimental period. The pre-intervention crime count and a dichotomous variable representing assignment to the treatment (1) or control (0) group were the model covariates. The difference in geographic size across the experimental areas was controlled for with a variable denoting the total length (ft.) of the street segments encompassed by the CCTV scheme (Sorg et al. 2013). To ensure that coefficient variances were robust to the presence of heteroscedasticity, robust standard errors were used (Braga and Bond 2008). To account for the matching used in the random assignment, the models incorporated the standard errors for each of the 19 pairs of CCTV schemes. It should be noted that we obtained similar results when traditional robust variances were calculated. ${ }^{11}$ For each crime category experiencing a statistically significant reduction, a Weighted Displacement Quotient (WDQ) was calculated, with negative values suggesting displacement and positive values suggesting a diffusion of benefits (Bowers and Johnson 2003: p. 286). Finally, a Total Net Effect (TNE), which measures the overall effect of the response on crime in the target area relative to changes in the control and catchment areas (Clarke and Eck 2005: step 51; Guerette 2009: p. 43), was calculated for each model reporting a statistically significant

\footnotetext{
${ }^{9}$ As will be discussed later in the text, experiment effect on crime was measured across three different time periods. Additional $t$ tests conducted for each of these time periods further demonstrated balance between treatment and control areas, with test statistics not achieving significance in a single instance. Due to limited space, the $t$ tests results are not presented in text, but are available from the lead author upon request.

${ }^{10} X^{2}$ goodness-of-fits tests conducted after exploratory Poisson regression models confirmed that each crime type was distributed as a negative binomial process. For the "Tours" models: Violence, Pearson $X^{2}=57.05, p=$ 0.01; Disorder, Pearson $X^{2}=65.18, p=0.001$; Narcotics, Pearson $X^{2}=56.06, p=0.01$. For the "Days" models: Violence, Pearson $X^{2}=62.75, p=0.002$; Disorder, Pearson $X^{2}=92.98, p=0.000$; Narcotics, Pearson $X^{2}=67.39$, $p=0.001$. For the "11-Week" models: Violence, Pearson $X^{2}=63.89, p=0.001$; Disorder, Pearson $X^{2}=133.19$, $p=0.000$; Narcotics, Pearson $X^{2}=106.10, p=0.000$. For all tests $\mathrm{df}=34$.

${ }^{11}$ We recognize that another option was to conduct a multi-level analysis treating the number of events in the pretest period as a random effect across the 19 pairs of schemes. However, due the small size of the level one sample (pairs of schemes) and the fact that a single measurement was made during the "pre" and "post" periods, we concluded that a multi-level model was inappropriate for this data (Snijders 2005). This decision aligns with prior place-based policing experiments (see Braga and Bond 2008: p. 589, footnote 10).
} 


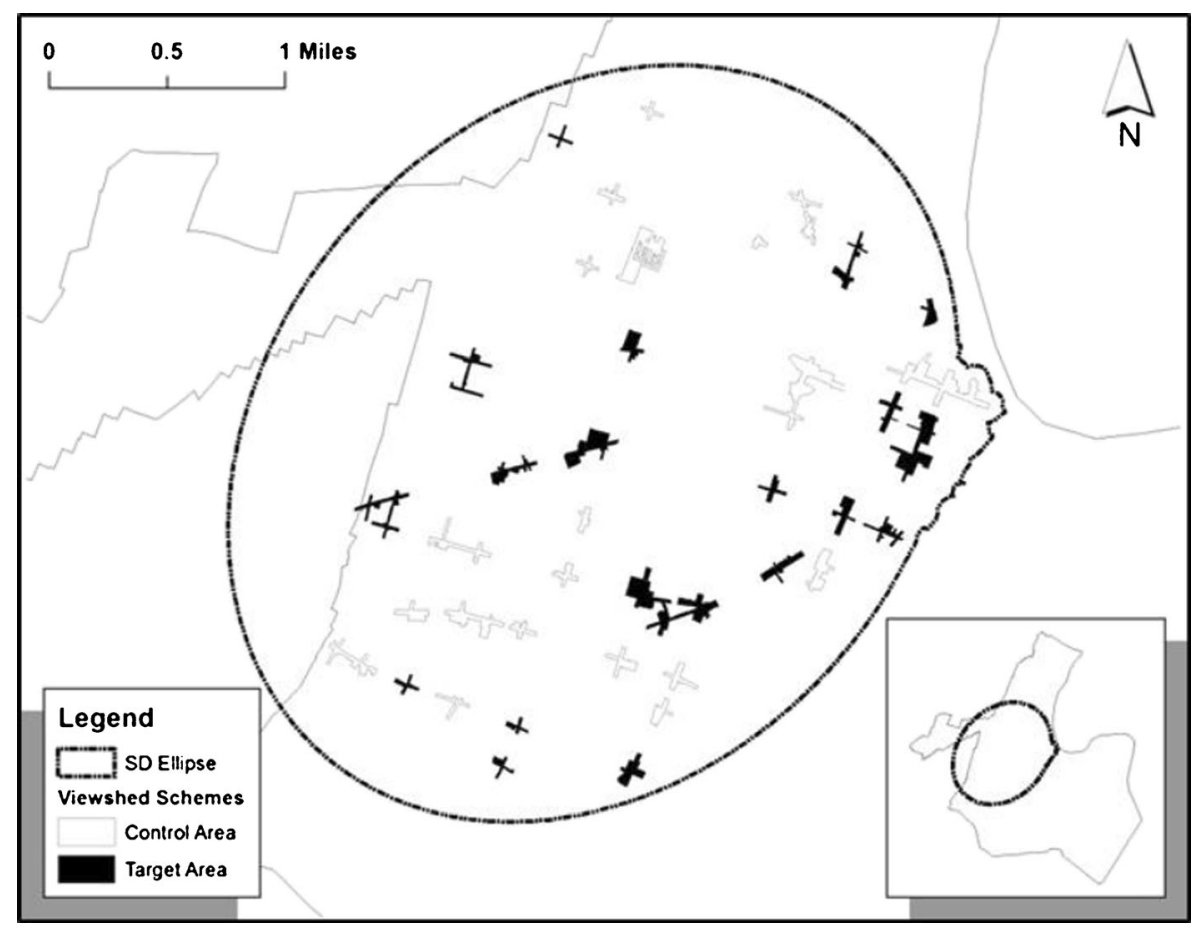

Fig. 2 Treatment CCTV schemes, control CCTV schemes, and the standard deviation ellipse

reduction. The WDQ and TNE values were calculated in Ratcliffe and Breen's (2008) Spatial Evaluation of Police Tactics in Context (SEPTIC) tool.

Crime prevention effects were measured for three distinct time periods. Different time periods were incorporated to provide multiple measures of experiment effect and to ensure that the observed results were not merely the byproduct of a single temporal parameter. The first time period was the experiment tours of duty (Wednesday through Saturday, $8 \mathrm{pm}$ to midnight from $7 / 20 / 11$ to $10 / 1 / 11$ ). The second time period was the entire days (e.g., 24-h period) the experimental tours took place, in recognition of previous studies finding that temporally limited activity may produce deterrence effects lasting the entire day (Telep et al. 2012). Finally, crime was measured for the entire 11week experimental period (7/20/11 to $10 / 1 / 11)$. Since we expected that the experiment would result in increased enforcement in target areas, we recognized the possibility that deterrence effects generated by enforcement may have lasted several days, as observed in prior research (Wyant et al. 2012). To account for seasonal cycles in crime data (Hipp et al. 2004; McDowall et al. 2012), each time period was compared to the same time period from the previous year (i.e., 7/8/11, the third Friday in July 2011, was compared with $7 / 9 / 10$, the third Friday in July 2010), following the approach of recent placebased policing experiments (e.g., Telep et al. 2012).

While the multiple time periods allowed for repeated exploration of the research question, it increased the possibility of committing a Type I error by subjecting each crime type to multiple significance tests, commonly referred to as the alpha inflation issue. The traditional procedure for controlling alpha inflation is the Bonferroni method, where each obtained $p$ value is multiplied by the number of tests performed and 
then compared to the target $p$ value (Belkap 1992). However, the Bonferroni method, as well as modified Bonferroni procedures like the Holm-Bonferroni method (Holm 1979), have the serious problem of increasing the chance for committing a Type II error by reducing statistical power (Olejnik et al. 1997; Sankoh et al. 1997). This issue is particularly troublesome in the current study given the low statistical power of the analysis (discussed below). In addition, study-wide Bonferroni correction methods exclusively address the hypothesis that the treatment and control groups are identical across all dependent variables, and ignore the importance of understanding differences across specific variables (Perneger 1998). As argued by Perneger (1998), a clinical equivalent of this scenario is "the case of a doctor who orders 20 different laboratory tests for a patient, only to be told that some are abnormal, without further detail" (p. 1237). This has led to significant backlash against the application of Bonferroni corrections to statistical findings, particularly in the medical field (Perneger 1998, 1999; Feise 2002).

These aforementioned issues informed our alpha inflation correction. Rather than using a study-wide correction, we incorporated the Dubey/Armitage-Parmer approach (Sankoh et al 1997: p. 2534-2535) of accounting for the correlations amongst the dependent variables in the alpha corrections. As illustrated by Garcia (2004), when dependent variables are significantly correlated "the approach used should account for variable dependence while correcting for alpha inflation" to maintain statistical power by allowing for the adjusted alpha level to be closer to the desired alpha level when the dependent variables are strongly correlated (p. 659). Since we were interested in detecting whether the experiment had differential effect across crime types, alpha corrections were conducted for the three tests conducted for each crime category (violent crime, social disorder, and narcotics offenses) rather than the nine tests conducted across all categories. As will be discussed later, this enabled us to identify specific crime types that were more impacted by the experiment than others. We used the web-based statistical program SISA to estimate the adjusted $p$ value for our statistical tests, accounting for our desired alpha, number of tests, average correlation, 12 and degrees of freedom (Uitenbroek 1997).

\section{Results}

\section{Process evaluation}

Our analysis begins with a brief process evaluation of the experiment. While evaluations of police interventions often only include tests of outcome measures, process measures allow researchers to contextualize program effects and more readily extract policy implications from the findings (Sherman and Eck 2002). To review, we expected that the mechanism through which the experimental strategy would reduce crime was an increase in certainty of punishment within target areas. This increased punishment certainty was expected to be generated from increased CCTV detections and the

\footnotetext{
${ }^{12}$ Separate correlation matrices were created for the main and residual models, which are discussed below. Given limited space, the correlation matrices are not presented in text, but are available from the lead author upon request.
} 
subsequent enforcement actions carried out by the experimental patrol officers. Therefore, we measured two process measures: reported detections of the experimental CCTV operators and the enforcement actions of the experimental patrol officers.

In total, the experimental operators reported 74 incidents of concern to the patrol officers. Most of the activity was related to the drug trade, with 55 of the $74(74.3 \%)$ of the reported detections classified as narcotics-related. ${ }^{13}$ Sixty-four $(56.5 \%)$ of the detections resulted in an enforcement action. Thirty-nine of the 64 enforcement actions $(60.9 \%)$ were arrests. The remaining $25(39.0 \%)$ were record checks or field interrogations. ${ }^{14}$ This represents a drastic increase in enforcement when compared with the standard CCTV operation. Only four detections and four enforcement actions were conducted within the treatment schemes during the pre-intervention period $(7 / 21 / 10$ to 10/2/10). Furthermore, during the 52 weeks preceding the experiment, the entire 146camera system averaged only 1.5 detections and 0.71 enforcement actions per week. We concluded that the experiment was implemented as intended, with an increase in CCTV activity, and perceived certainty of punishment, being achieved. ${ }^{15}$

\section{Outcome evaluation}

\section{Statistical power}

Before presenting the results of the outcome evaluation, we will discuss the statistical power of the analysis. The small sample size coupled with the concise study period caused the experiment to be underpowered. The experiment included only 19 treatment areas and 19 controls areas and ran for an 11-week period. Given a sample of 19 treatment locations, the experiment had about a $10 \%$ chance of detecting a small effect of 0.2 , about a $30 \%$ chance of detecting a medium effect of 0.5 , and about a $70 \%$ chance of detecting a large effect size of 0.8 (Lipsey 1990), as defined by Cohen (1988). ${ }^{16}$ While prior place-based policing experiments have incorporated similar sample sizes they have typically occurred for longer periods of time than the current

\footnotetext{
${ }^{13}$ It should be noted that, since these events were not reported via CAD, the operator activity was not captured within the calls-for-service counts. Thus, the analysis of outcome measures was not influenced by operator activity.

${ }^{14}$ Record checks refer to incidents where police officers detain a suspect at the scene and contact the communications division via radio to ascertain whether the individual has any open warrants, or is otherwise wanted for a crime. Field interrogations refer to instances where police officers detain a suspect at the scene and question them regarding the incident observed by the CCTV operator. In most cases, record checks and field interrogations were conducted in unison, so we report them both together as "other enforcement". In the event an arrest occurred as a result of a record check or field interrogation, the incident was counted as an arrest. Therefore, the enforcement categories are mutually exclusive.

${ }^{15}$ While each of these 64 enforcement actions occurred within the treatment area, there were two incidents (which are not reflected in these figures) where patrol officers enacted a proactive enforcement action outside of the treatment area. In one instance, a patrol unit was flagged down by a pedestrian who reported that he had just been robbed at gunpoint. The officers thus pursued and apprehended the suspect. In the other instance, officers observed what they believed to be a hand-to-hand narcotics transaction between two males in front of a house. After detaining the suspects, the officers found both individuals to be in possession of narcotics and placed both of them under arrest. It is important to note that these two incidents had no bearing on the evaluation since both arrests occurred outside of both the treatment and control schemes.

${ }^{16}$ As explained by Lipsey (1990), in statistical power calculations "[s]ample size refers to the number of subjects in each group - for example, ten treatment subjects compared with ten control subjects is represented as a sample size of 10 " (p. 71: emphasis in original text).
} 
experiment. For example, Braga (1997), Braga and Bond (2008), and Weisburd and Green (1995) incorporated only 12, 17, and 28 target areas, respectively. However, interventions occurred for approximately 1 year in the Braga (1997) and Braga and Bond (2008) studies and 15 months in the case of Weisburd and Green (1995). This suggests the small sample in the current experiment may have had a more negative effect on power than in previous experiments. ${ }^{17}$

Post hoc analysis of our statistical tests also suggested that our design was underpowered. This post hoc analysis, conducted in the $\mathrm{G}^{*}$ Power software package (Faul et al. 2009), revealed that the statistical tests achieved statistical power ranging from 0.15 to 0.53 , with none meeting the standard power level of 0.80 (Britt and Weisburd 2010). To increase statistical power, we set the alpha level for statistical significance at 0.10 , rather than 0.05 , in order to minimize the chance of making a Type II error of falsely failing to reject the null hypothesis (Lipsey 1990). Prior underpowered experiments have similarly incorporated alpha levels of 0.10 in order to protect against Type II errors (see Weisburd and Green 1995). ${ }^{18}$

\section{Main effects}

Table 1 displays the pre and during intervention crime counts for the treatment and control schemes across the three time periods. Crime counts reduced within the treatment areas in seven of a possible nine instances. In comparison, control areas experienced a reduction in crime counts in only two instances. The statistical significance of these changes was tested via negative binomial regression models.

Table 2 displays the results of the statistical models over the three time periods. The treatment variable was statistically significant in four of nine instances, each suggestive of a crime decrease within treatment areas. During the "tours" period, assignment to the treatment group was associated with a violent crime reduction of $48 \%(I R R=0.52)$ and a social disorder reduction of $49 \%(\mathrm{IRR}=0.51)$. During the "days" period, violent crime reduced $40 \%(I R R=0.60)$ in the treatment areas compared to the control areas. During the 11 -week experiment period, social disorder $(I R R=0.59)$ achieved statistically significant $41 \%$ reduction. All of these results maintained their statistical significance following the application of the SISA alpha inflation adjustment. Assignment to the treatment group had no effect on narcotics activity in any model.

\footnotetext{
${ }^{17}$ Increasing sample size is typically considered as the most straightforward way to increase statistical power. However, as noted by Weisburd et al. (1993), increasing sample size may negatively affect field experiments by creating a treatment group too large for each case to receive proper dosage. Indeed, Buerger (1993) reported that such an instance occurred in the Minneapolis RECAP experiment (Sherman et al. 1989). We, therefore, decided to not increase our sample size at the outset of the experiment in order to protect against spreading the treatment too thinly across the treatment area.

${ }^{18}$ It is common practice for a pre-intervention power analysis, identifying the necessary sample size to achieve statistical power, to guide the scope of experimental studies. Unfortunately, the changing fiscal situation of the Newark Police Department reduced the anticipated scope of the experiment. The grant funding this experiment provided funds for officers to work the experiment over 20 separate 4-h tours of duty. The Newark Police Department originally agreed to dedicate additional resources towards the experiment so that more tours-ofduty could be implemented. Unfortunately, prior to the start of the experiment extreme budget cuts led to the termination of 167 police officers in Newark (Star Ledger 2010). This led the newly appointed police leadership to determine that the Department could no longer afford to dedicate additional resources towards the experiment.
} 
Table 1 Raw crime counts

\begin{tabular}{|c|c|c|c|c|c|c|c|c|c|}
\hline & \multicolumn{3}{|c|}{ Tours } & \multicolumn{3}{|c|}{ Days } & \multicolumn{3}{|c|}{ 11-weeks } \\
\hline & Pre & During & Difference & Pre & During & Difference & Pre & During & Difference \\
\hline \multicolumn{10}{|l|}{ Violent crime } \\
\hline Control & 21 & 34 & 13 & 72 & 84 & 12 & 130 & 123 & -7 \\
\hline Treatment & 40 & 25 & -15 & 107 & 74 & -33 & 186 & 130 & -56 \\
\hline \multicolumn{10}{|c|}{ Social disorder } \\
\hline Control & 22 & 48 & 26 & 100 & 115 & 15 & 183 & 195 & 12 \\
\hline Treatment & 40 & 45 & 5 & 151 & 140 & -11 & 273 & 210 & -63 \\
\hline \multicolumn{10}{|c|}{ Narcotics activity } \\
\hline Control & 21 & 44 & 23 & 63 & 44 & -19 & 101 & 73 & -28 \\
\hline Treatment & 17 & 41 & 24 & 77 & 41 & -36 & 112 & 82 & -30 \\
\hline
\end{tabular}

$N=38$ (19 Treatment; 19 Control)

Table 3 displays the results of the displacement analysis. Across the three time intervals, a weighted displacement quotient was calculated for each crime category that experienced a reduction. In each instance, Phi statistics suggest that the WDQ

Table 2 Negative binomial regression results, crime incidents (main effects: 7/20/11-10/1/11)

\begin{tabular}{|c|c|c|c|c|c|c|c|c|c|}
\hline \multirow[t]{2}{*}{ Covariates } & \multicolumn{3}{|c|}{ Tours } & \multicolumn{3}{|l|}{ Days } & \multicolumn{3}{|c|}{ 11-weeks } \\
\hline & IRR & Robust S.E. & p. & IRR & Robust S.E. & p. & IRR & Robust S.E. & p. \\
\hline \multicolumn{10}{|l|}{ Violent crime } \\
\hline Treatment & 0.52 & 0.17 & $0.05^{*}$ & 0.60 & 0.15 & $0.05^{*}$ & 0.78 & 0.14 & 0.17 \\
\hline Pre crime count & 1.18 & 0.05 & $0.00 *$ & 1.09 & 0.02 & $0.00 *$ & 1.04 & 0.01 & $0.00^{*}$ \\
\hline Geographic unit size & 0.99 & 0.00 & 0.76 & 1.00 & 0.00 & 0.48 & 1.00 & 0.00 & 0.16 \\
\hline \multicolumn{10}{|l|}{ Social disorder } \\
\hline Treatment & 0.51 & 0.17 & $0.04 *$ & 0.67 & 0.19 & 0.16 & 0.59 & 0.14 & $0.02 *$ \\
\hline Pre crime count & 1.41 & 0.11 & $0.00 *$ & 1.12 & 0.02 & $0.00 *$ & 1.07 & 0.01 & $0.00^{*}$ \\
\hline Geographic unit size & 1.00 & 0.00 & $0.01 *$ & 1.00 & 0.00 & $0.00 *$ & 1.00 & 0.00 & $0.02 *$ \\
\hline \multicolumn{10}{|l|}{ Narcotics activity } \\
\hline Treatment & 0.94 & 0.35 & 0.86 & 0.73 & 0.26 & 0.37 & 0.88 & 0.30 & 0.71 \\
\hline Pre crime count & 1.52 & 0.09 & $0.00 *$ & 1.12 & 0.04 & $0.02 *$ & 1.08 & 0.02 & $0.00 *$ \\
\hline Geographic unit size & 0.99 & 0.00 & $0.00^{*}$ & 0.99 & 0.00 & $0.01 *$ & 0.99 & 0.00 & $0.00^{*}$ \\
\hline
\end{tabular}

$N=38$ (19 Treatment; 19 Control)

The size of the geographic unit is measured as total length (in feet) of the encompassed street segments Robust standard errors calculated for 19 clusters of CCTV scheme pairs

Average correlation across dependent variables, $r_{\text {violence }}=0.65 ; r_{\text {social disorder }}=0.84 ; r_{\text {narocitcs }}=0.97$

*Statistically significant after SISA adjustment for alpha inflation (critical $p_{\text {violence }}=0.06 ; p_{\text {social disorder }}=0.08$; $p_{\text {narcotics }}=0.09$ ) 
Table 3 Weighted displacement quotients (main effects: 7/20/11-10/1/11)

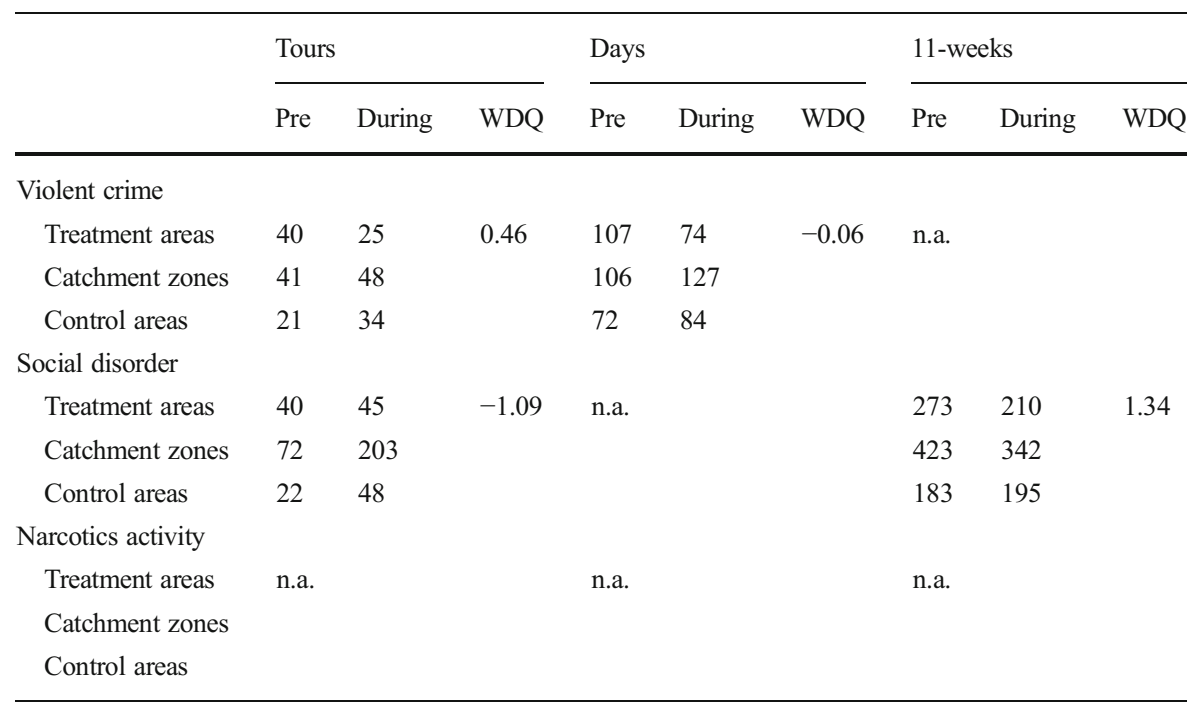

calculations were statistically significant (Ratcliffe and Breen 2008). For the "tours" period, violent crime and social disorder experienced diffusion of benefits and displacement effects, respectively. The WDQ value for violent crime (0.46) suggests a diffusion of benefits effect less than the direct effects in the treatment area. For social disorder, the WDQ of -1.09 demonstrates that the catchment zone experienced a displacement effect greater than the achieved reduction in the treatment area. For the "days" period, violent crime's WDQ suggests no real displacement or diffusion effects $(-0.06)$. For the 11-week period, social disorder experienced a diffusion of benefits that was greater than the reduction in the target area (1.34).

\section{Residual effects}

Additional analyses tested the effect of the experiment on crime counts following the conclusion of the intervention, a phenomenon Sherman (1990) referred to as "residual deterrence." To test the residual effect of the current experiment, three additional negative binomial regression models were conducted. The models mirrored the time periods of the main analysis: "residual tours" (Wednesday through Saturday, $8 \mathrm{pm}$ to midnight, from $10 / 5 / 11$ to $12 / 17 / 11$ ); "residual days" (Wednesday through Saturday, from $10 / 5 / 11$ to $12 / 17 / 11)$; and "residual 11-weeks" (10/5/11-12/17/11). As with the main analysis, each time period was compared to the same time period from the previous year.

Table 4 displays the results of the residual models. Narcotics Activity during the "residual days" period was the only instance where assignment to the treatment group was associated with a statistically significant reduction $(\mathrm{IRR}=0.51 ; p=0.07)$. This result maintained statistical significance following the application of the SISA alpha inflation adjustment. However, the WDQ calculated for this finding $(-1.24)$ 
Table 4 Negative binomial regression results, crime incidents (residual effects: 10/5/11-12/17/11)

\begin{tabular}{|c|c|c|c|c|c|c|c|c|c|}
\hline \multirow[t]{2}{*}{ Covariates } & \multicolumn{3}{|l|}{ Tours } & \multicolumn{3}{|l|}{ Days } & \multicolumn{3}{|c|}{ 11-weeks } \\
\hline & IRR & Robust S.E. & p. & IRR & Robust S.E. & p. & IRR & Robust S.E. & p. \\
\hline \multicolumn{10}{|l|}{ Violent crime } \\
\hline Treatment & 0.50 & 0.23 & 0.13 & 0.82 & 0.22 & 0.47 & 0.98 & 0.19 & 0.91 \\
\hline Pre crime count & 1.65 & 0.15 & $0.00^{*}$ & 1.11 & 0.02 & $0.00 *$ & 1.08 & 0.01 & $0.00^{*}$ \\
\hline Geographic unit size & 1.00 & 0.00 & 0.92 & 1.00 & 0.00 & 0.47 & 1.00 & 0.00 & 0.28 \\
\hline \multicolumn{10}{|l|}{ Social disorder } \\
\hline Treatment & 0.96 & 0.38 & 0.91 & 1.25 & 0.34 & 0.41 & 1.18 & 0.31 & 0.53 \\
\hline Pre crime count & 1.23 & 0.11 & $0.02 *$ & 1.05 & 0.02 & $0.00 *$ & 1.03 & 0.01 & $0.00^{*}$ \\
\hline Geographic unit size & 1.00 & 0.00 & 0.21 & 0.99 & 0.00 & $0.03 *$ & 1.00 & 0.00 & 0.08 \\
\hline \multicolumn{10}{|l|}{ Narcotics activity } \\
\hline Treatment & 0.23 & 0.27 & 0.21 & 0.51 & 0.19 & $0.07 *$ & 0.69 & 0.21 & 0.23 \\
\hline Pre crime count & 1.74 & 0.34 & $0.01^{*}$ & 1.11 & 0.02 & $0.00 *$ & 1.08 & 0.02 & $0.00 *$ \\
\hline Geographic unit size & 0.99 & 0.00 & 0.66 & 0.99 & 0.00 & 0.49 & 0.99 & 0.00 & 0.18 \\
\hline
\end{tabular}

$N=38$ (19 Treatment; 19 Control)

The size of the geographic unit is measured as total length (in feet) of the encompassed street segments Robust standard errors calculated for 19 clusters of CCTV scheme pairs

Average correlation across dependent variables, $r_{\text {violence }}=0.68 ; r_{\text {social disorder }}=0.72 ; r_{\text {narocitcs }}=0.81$

*Statistically significant after SISA adjustment for alpha inflation (critical $p_{\text {violence }}=0.07 ; p_{\text {social disorder }}=0.07$; $p_{\text {narcotics }}=0.08$ )

suggests a displacement effect larger than the reduction experienced in the target area. ${ }^{19}$

\section{Total net effects}

Total Net Effect (TNE) values suggest a crime reduction in a total of three instances. For violent crime, the experiment produced a reduction of 58 incidents in the "tours" period and a reduction of 47 incidents in the "days" period. Social disorder experienced a reduction of 189 incidents in the "11-week" period. The experiment was associated with an increase of social disorder during the "tours" period and narcotics activity during the "days" period. However, in each instance the increase was only three incidents, a very modest figure in comparison to the aforementioned decreases. Furthermore, since social disorder reduced by 189 incidents during the "11-week" period, with a diffusion of benefits greater than the target area reduction, the "tour" increase of three incidents is arguably negligible. Therefore, the TNE statistics suggest that the experiment produced sizable crime decreases with minimal negative effects (Table 5).

\footnotetext{
${ }^{19}$ Crime in both the treatment and catchment zones experienced a reduction (from 80 to 38 incidents and from 87 to 77 incidents, respectively) during the "residual days" period. However, the control area also experienced a sizable decline (from 42 to 28 incidents), which led to the negative WDQ.
} 
Table 5 Total net effects (across both main and residual periods)

\begin{tabular}{lccc}
\hline & Tours & Days & 11 weeks \\
\hline $\begin{array}{l}\text { Violent crime } \\
\text { Incident increase/decrease }\end{array}$ & -58 & -47 & n.a. \\
$\begin{array}{l}\text { Social disorder } \\
\text { Incident increase/decrease }\end{array}$ & +3 & n.a. & -189 \\
$\begin{array}{l}\text { Narcotics activity } \\
\text { Incident increase/decrease }\end{array}$ & n.a. & +3 & n.a. \\
\hline
\end{tabular}

\section{Discussion of results}

Results suggest that the experimental strategy had a positive effect on Newark's CCTV operation, producing tangible and meaningful crime reductions of violent crime and social disorder. Examination of the IRR and TNE values suggests that these crime reductions were sizable in many instances. While potential backfire effects were observed in two instances, they were very modest in comparison to the crime decreases, and, in the case of social disorder, were negated by large decreases during other time periods. Furthermore, when considered in context of the overall findings, the social disorder "tours" finding may represent an instance of "benign displacement," which Barr and Pease (1990) define as a redistribution of crime patterns from a more serious state to a less serious state. As an example of benign displacement, Barr and Pease (1990) discussed a debate around gun control. They argued that even in the unlikely event that a reduction in gun assaults was completely negated by displacement to knife assaults the observed displacement would be benign since the more lethal weapon (gun) was replaced with a less lethal weapon (knife). In this sense, officials may consider the prevention of serious violent crime to be worth a slight increase in relatively minor incidents of social disorder.

Somewhat curious findings were observed in respect to narcotics offenses. Narcotics incidents did not reduce in a single instance during the experiment, despite the fact that officers spent most of their time addressing narcotics-related incidents. The illicit drug trade has long been known to generate a number of ancillary public safety concerns, including violence and disorder (Harocopos and Hough 2005). It may be that police response to narcotics incidents prevented ancillary violence or disorder from taking place without substantially disrupting drug markets themselves. With that said, narcotics offenses experienced a significant decrease during the "residual days" period. However, this residual deterrence in the treatment areas was met with an increase of three narcotics activity incidents in the catchment zone. These findings beg the question of why narcotics offenders seemingly relocated their operations after the conclusion of the experiment, but not during the actual intervention. This may be at least partially due to the resiliency of drug markets, which are recognized as being largely immune to street-level police enforcement (Gajewski 1994; Kennedy and Wong 2009; Weisburd et al. 2006). As argued by Kennedy (2006), "[a] street drug dealer may have been arrested a number of times. But each day, when he considers whether to go to work his 
corner, the chance that he will be arrested today will be...small" (p. 165: emphasis in original text). It may have been that, while enforcement deterred violent and disorderly offenders from the outset of the experiment, the entire experiment's worth of enforcement may have been necessary for narcotics offenders to collectively recognize the heightened risk of apprehension in the treatment areas. The spatial displacement of narcotics offenses may be explained by its difference from other crime types. Offenders motivated by monetary profit (i.e., drug offenders) are more likely to displace their activities to nearby areas than other offenders (Guerette et al. 2005). While Weisburd et al. (2006), for example, found that drug dealers did not relocate their operation in response to a place-based narcotics initiative, drug offenders in the current study may have found it easier to relocate. Since CCTV cameras have a limited view of a block or so, "relocating" a drug market may only entail traveling a handful of feet (i.e., immediately around the corner or across the street) to an area out of camera view. Drug offenders interviewed by Gill and Loveday (2003) reported that they were easily able to escape detection by conducting business in camera blind spots, or just beyond the visual reach of CCTV. This contrasts with offenders not driven by money, who would have to travel greater distances from CCTV and who would receive little benefit by doing so, when they are blocked from committing their intended crime at their preferred location. As Piza and O'Hara (2014) argued, "It is unlikely that a slighted bar patron, for example, would respond to a thwarted opportunity to attack someone in front of the establishment by traveling outside of the target area and attacking a person not involved in the quarrel" (p. 711).

\section{Policy implications and conclusions}

In our view, the results of this study make the experimental strategy a viable option for jurisdictions with existing CCTV infrastructure, specifically those burdened with high levels of street crime. While the current study involved assignment of additional personnel to the CCTV operation to conduct the experimental strategy, alternate options may exist for police to lower camera-to-operator ratios and avoid the differential response deployment of officers in response to CCTV detections. Research suggests that CCTV installation should be preceded by an in-depth analysis of the spatial distribution and nature of crime patterns (Ratcliffe 2006; Welsh and Farrington 2002). Such analysis could also be incorporated into existing CCTV operations to determine whether a higher priority for active monitoring should be given to certain cameras over others. For instance, a spatial analysis of crime could identify specific camera sites experiencing higher levels of crime than others. In such a case, these cameras could be actively monitored while the others are only viewed in a post-hoc manner after a crime has been reported. Furthermore, the concentration of crime may not be temporally consistent, but may fluctuate across times of the day or days of the week. Operator attention can be further focused by having them actively monitor only those cameras most at-risk of experiencing crime during their particular tours-of-duty. The Chicago Police Department utilizes such a strategy in which a dozen or so CCTV locations are prioritized for active monitoring each day. A list of such locations is disseminated as "missions" to the Crime Prevention Information Center (CPIC) and the Office of Emergency Management and Communications (OEMC), who are responsible 
for the proactive monitoring of the priority cameras (La Vigne et al. 2011: p. 56). As noted by Piza et al. (2012), such a strategy is consistent with hot spots policing, which has consistently demonstrated the concentration of resources amongst a few problematic targets to be more effective than the even distribution of resources across space (Braga et al. 2012; Braga and Weisburd 2010; Weisburd 2008).

Regarding police response, CCTV operations can make more use of proactive police units (i.e., undercover narcotics units or foot patrol officers) rather than standard patrol units. Since such units typically are not responsible for responding to calls for service they can immediately address incidents detected by CCTV operators. This would drastically reduce the large police response times inherent in the differential response policy of police dispatch. Such tactics have been successfully incorporated by police. In Baltimore, for example, CCTV operators routinely alerted officers from the narcotics and bicycle units when they observed incidents on cameras within specific target areas (La Vigne et al. 2011).

Despite these policy implications, the current study, like most research, suffers from certain limitations that warrant mentioning. For one, the outcome analysis suffered from low statistical power. To minimize the chance of a Type II error, a $90 \%$ confidence interval was used rather than the more traditional $95 \%$, an approach incorporated in previous underpowered experiments (Weisburd and Green 1995). However, it should be noted that significance was $p<0.05$ (prior to alpha inflation correction) in each of the reductions observed across the "main" analyses. This may have been due to the randomized block design, which has been demonstrated to maintain statistical power even in the case of small sample sizes (Weisburd and Gill 2014). We advocate for the use of larger samples and longer study periods than what was incorporated in the current study, when feasible.

Regarding the increase in CCTV detections and subsequent enforcement, we largely attributed the increased activity to the lowering of the camera-to-operator ratio and elimination of differential response deployment, in recognition of prior research (Piza et al. 2012, 2014b). However, since the experimental operators were new to the operation, they may have approached CCTV monitoring with a higher level of vigilance than the standard operators, who had all worked in the surveillance unit for a considerable amount of time. Prior research has found that CCTV operators often experience decreased vigilance when they have spent considerable time working in surveillance units (Norris and McCahill 2006). Future research should account for such factors by using the standard CCTV operators in the experiment, or by shifting the experimental operators between the treatment and control groups.

In all, and given these qualifications, this experiment produced meaningful results with relatively minimal personnel resources. Only two patrol cars and one CCTV operator were needed for this 4-h per day, 4-days per week, 11week intervention to achieve sizable reductions in street crime. More generally, the findings add support to the hypothesis that the integration of CCTV with proactive, focused police activity generates a crime control benefit greater than what research suggests is achievable via stand-alone camera deployment. We recommend that future research continues to test and expand upon this proposition. 
Acknowledgments This research was supported by the National Institute of Justice, Grant Number 2010-IJCX-0026. We are truly indebted to a number of individuals at the Newark Police Department whose support made this project possible, including former Director Garry McCarthy, former Director Samuel DeMaio, former Chiefof-Staff Gus Miniotis, Captain Phil Gonzalez, Lieutenant Joseph Alferi, Lieutenant Brian O'Hara, Lieutenant Angelo Zamora, Sergeant Marvin Carpenter, and Sergeant Catherine Gasavage. We are especially grateful to the CCTV operators, patrol supervisors, and patrol officers who worked on the experiment for diligently carrying out their experimental tasks. We also thank Editor-in-Chief Lorraine Mazerolle, Associate Editor Emma Antrobus, and the anonymous reviewers for their helpful comments.

\section{References}

Ariel, B., \& Farrington, D. (2010). Randomized block designs. In A. Piquero \& D. Weisburd (Eds.), Handbook of quantitative criminology. New York: Springer.

Armitage, R., Smythe, G., \& Pease, K. (1999). Burnley CCTV evaluation. In N. Tilley \& K. Painter (Eds.), Surveillance of public space: CCTV, street lighting and crime prevention (Crime Prevention Studies, Vol. 10, pp. 225-249). Monsey: Criminal Justice Press.

Barr, R., \& Pease, K. (1990). Crime placement, displacement and deflection. In M. Tonry \& N. Morris (Eds.), Crime and justice: a review of research (Vol. 12, pp. 277-218). Chicago: University of Chicago Press.

Belkap, J. (1992). Empirical estimates of Bonferroni corrections for use in chromosome mapping studies with the BXD recombinant inbred strains. Behavior Genetics, 22(6), 677-684.

Bowers, K., \& Johnson, S. (2003). Measuring the geographical displacement and diffusion of benefit effects of crime prevention activity. Journal of Quantitative Criminology, 19, 275-301.

Braga, A. (1997). Solving violent crime problems: an evaluation of the Jersey City Police Department's pilot program to control violent places. Doctoral Dissertation submitted to the Graduate School-Newark, Rutgers, The State University of New Jersey.

Braga, A. (2010). Setting a higher standard for the evaluation of problem-oriented policing initiatives. Criminology \& Public Policy, 9(1), 173-182.

Braga, A., \& Bond, B. J. (2008). Policing crime and disorder hot spots: a randomized controlled trial. Criminology, 46(3), 577-607.

Braga, A., \& Weisburd, D. (2010). Policing problem places: crime hot spots and effective prevention. New York: Oxford University Press.

Braga, A., Weisburd, D., Waring, E., Mazerolle, L., Spelman, W., \& Gajewski, F. (1999). Problem-oriented policing in violent crime places: a randomized controlled experiment. Criminology, 37(3), 541-580.

Braga, A., Papachristos, A., \& Hureau, D. (2012). The effects of hot spots policing on crime: an updated systematic review and meta-analysis. Justice Quarterly. Advance online publication. doi: 10.1080/ 07418825.2012 .673632 .

Brantingham, P.L., \& Brantingham, P.J. (1998). Mapping crime for analytic purposes: location quotients, counts and rates. In Weisburd, D., \& McEwen, T. (Eds) Crime Mapping and Crime Prevention. Crime Prevention Studies, 8, 263-288.

Britt, C., \& Weisburd, D. (2010). Statistical power. In P. Alex \& D. L. Weisburd (Eds.), Handbook of quantitative criminology. New York: Springer.

Brown, B. (1995). CCTV in town centres: three case studies (Crime Detection and Prevention Series, Paper 68). London: Home Office.

Buerger, M. (1993). Convincing the recalcitrant: reexamining the Minneapolis RECAP experiment. Doctoral dissertation, Rutgers University.

Butler, G. (1994). Shoplifters' views on security: lessons for crime prevention. In M. Gill (Ed.), Crime at work: studies in security and crime prevention. London: Perpetuity Press.

Cameron, A., Kolodinski, E., May, H., \& Williams, N. (2008). Measuring the effects of video surveillance on crime in Los Angeles. Report prepared for the California Research Bureau. USC School of Policy, Planning, and Development.

Caplan, J., Kennedy, L., \& Petrossian, G. (2011). Police-monitored cameras in Newark, NJ: a quasiexperimental test of crime deterrence. Journal of Experimental Criminology, 7(3), 255-274.

Clarke, R. (1997). Introduction. In R. Clarke (Ed.), Situational crime prevention, successful case studies (2nd ed.). Monsey: Criminal Justice Press.

Clarke, R., \& Eck, J. (2005). Crime analysis for problem solvers in 60 small steps. Washington, DC: U.S. Department of Justice Office of Community Oriented Policing Services. 
Clarke, R., \& Weisburd, D. (1994). Diffusion of crime control benefits. In R. Clarke (Ed.), Crime prevention studies (Vol. 2, pp. 165-183). Monsey: Criminal Justice Press.

Cohen, J. (1988). Statistical power analysis for behavioral sciences (2nd ed.). Hillsdale: Lawrence Erlbaum.

Cornish, D., \& Clarke, R. (Eds.). (1986). The reasoning criminal: rational choice perspectives on offending. New York: Springer.

Cowan, N. (2000). The magical number 4 in short-term memory: a reconsideration of mental storage capacity. Behavioral and Brain Sciences, 42, 87-185.

Ditton, J., \& Short, E. (1998). Evaluating Scotland's first town centre CCTV scheme. In C. Norris, J. Moran, \& G. Armstrong (Eds.), Surveillance, closed circuit television and social control. Aldershot: Ashgate.

Ditton, J., \& Short, E. (1999). Yes, it works, no it doesn't: comparing the effects of open-street CCTV in two adjacent Scottish town centres. In N. Tilley \& K. Painter (Eds.), Surveillance of public space: CCTV, street lighting and crime prevention (Crime Prevention Studies, Vol. 10, pp. 201-223). Monsey: Criminal Justice Press.

Durlauf, S., \& Nagin, D. (2011). Imprisonment and crime: can both be reduced? Criminology and Public Policy, $10(1), 13-54$.

Eisner, M. (2009). No effects in independent prevention trials: can we reject the cynical view? Journal of Experimental Criminology, 5(2), 163-184.

Farrington, D., Gill, M., Waples, S., \& Argomaniz, J. (2007). The effects of closed-circuit television on crime: meta-analysis of an English national quasi-experimental multi-site evaluation. Journal of Experimental Criminology, 3, 21-28.

Faul, F., Erdfelder, E., Buchner, A., \& Lang, A. (2009). Statistical power analyses using G*Power 3.1: tests for correlation and regression analyses. Behavior Research Methods, 41(4), 1149-1160.

Feise, R. (2002). Do multiple outcome measures require p-value adjustment? BMC Medical Research Methodology, 2, 8-11.

Fyfe, N., \& Bannister, J. (1996). City watching: closed circuit television surveillance in public spaces. Area, $28(1), 37-46$.

Gajewski, F. (1994). The drug market analysis program: a participant observation study. Unpublished master's thesis, Seton Hall University: South Orange, NJ.

Garcia, L. (2004). Escaping the Bonferroni iron claw in ecological studies. Oikos, 105(3), 657-663.

Gill, M., \& Hemming, M. (2004). Evaluation of CCTV in the London borough of Lewisham. Leicester: Perpetuity Research \& Consultancy International (PRCI).

Gill, M., \& Loveday, K. (2003). What do offenders think about CCTV? Crime Prevention and Community Safety: An International Journal, 5(3), 17-25.

Gill, M., \& Spriggs, A. (2005). Assessing the impact of CCTV (p. 292). London: Home Office Research Study No.

Gill, M., \& Turbin, V. (1998). CCTV and shop theft: towards a realistic evaluation. In N. Clive, M. Jade, \& A. Gary (Eds.), Surveillance, closed circuit television and social control. Aldershot: Ashgate.

Gill, M., Spriggs, A., Allen, J., Hemming, M., Jessiman, P., \& Kara, D. (2005). Control room operation: findings from control room observations. London: Home Office.

Grant, S., Mayo-Wilson, E., Hopewell, S., MacDonald, S., Moher, D., \& Montgomery, P. (2013). Developing a reporting guideline for social and psychological intervention trials. Journal of Experimental Criminology, 9(3), 355-367.

Guerette, R. (2009). Analyzing crime displacement and diffusion. Problem-oriented guides for police. Problem-solving tools series. No. 10. U.S. Department of Justice Office of Community Oriented Policing Services. Center for Problem-Oriented Policing.

Guerette, R., Steinus, V., \& McGloin, M. (2005). Understanding offending specialization and versatility: a reapplication of the rational choice perspective. Journal of Criminal Justice, 33(1), 77-87.

Halford, G., Baker, R., McCredden, J., \& Bain, J. (2005). How many variables can humans process? Psychological Science, 16(1), 70-76.

Harocopos, A., \& Hough, M. (2005). Drug dealing in open air markets (Problem-Oriented Guides for Police. Problem-Specific Guides Series: No. 31). Washington, DC: U.S. Department of Justice. Office of Community Oriented Policing Services.

Hipp, J., Bauer, D., Curran, P., \& Bollen, K. (2004). Crimes of opportunity or crimes of emotion? Testing two explanation of seasonal change in crime. Social Forces, 82, 1333-1372.

Holm, S. (1979). A simple sequentially rejective multiple test procedure. Scandinavian Journal of Statistics, 6 , 65-70.

Kennedy, D. (2006). Old wine in new bottles: policing and the lessons of pulling levers. In D. Weisburd \& B. Anthony (Eds.), Police innovation. Contrasting perspectives. Cambridge: Cambridge University Press. 
Kennedy, D., \& Wong, S. (2009). The high point drug market intervention strategy. Washington, DC: Office of Community Oriented Policing Services, U.S. Department of Justice.

Keval, H., \& Sasse, M. (2010). "Not the usual suspects": a study of factors reducing the effectiveness of CCTV. Security Journal, 23(2), 134-154.

King, J., Mulligan, D., \& Raphael, S. (2008). CITRIS report: the San Francisco community safety camera program. An evaluation of the effectiveness of San Francisco's community safety cameras. Research in the interest of society. Berkeley: Center for Information Technology Research in the Interest of Society. University of California.

Klinger, D., \& Bridges, G. (1997). Measurement error in calls-for-service as an indicator of crime. Criminology, 35, 705-726.

La Vigne, N., Lowry, S., Markman, J., \& Dwyer, A. (2011). Evaluating the use of public surveillance cameras for crime control and prevention. Washington, DC: US Department of Justice, Office of Community Oriented Policing Services. Urban Institute, Justice Policy Center.

Law Enforcement Information Technology Standards Council [LEITSC] (2008). Standard functional specifications for law enforcement computer aided dispatch (CAD) systems. U.S. Department of Justice, Office of Justice Programs, Bureau of Justice Assistance, and the National Institute of Justice.

Lipsey, M. (1990). Design sensitivity. Statistical power for experimental research. Newbury Park: Sage.

Lomell, H. (2004). Targeting the unwanted: video surveillance and categorical exclusion in Oslo, Norway. Surveillance \& Society, 2, 346-360.

Luck, S., \& Vogel, E. (1997). The capacity of visual working memory for features and conjunctions. Nature, 390, 279-281.

Lum, C., Koper, C., \& Telep, C. (2011). The evidence-based policing matrix. Journal of Experimental Criminology, 7(3), 3-26.

Mazerolle, L., Hurley, D., \& Chamlin, M. (2002). Social behavior in public space: an analysis of behavioral adaptations to CCTV. Security Journal, 15(3), 59-75.

McDowall, D., Loftin, C., \& Pate, M. (2012). Seasonal cycles in crime, and their vulnerability. Journal of Quantitative Criminology, 28, 389-410.

McLean, S., Worden, R., \& Kim, M. (2013). Here's looking at you: an evaluation of public CCTV cameras and their effects on crime and disorder. Criminal Justice Review, 38(3), 303-334.

Nagin, D., \& Weisburd, D. (2013). Evidence and public policy. The example of evaluation research in policing. Criminology \& Public Policy, 12(4), 651-679.

Norris, C. (2003). From personal to digital: CCTV, the panopticon, and the technological mediation of suspicion and social control. In L. David (Ed.), Surveillance as social sorting: privacy, risk and digital discrimination. London: Routledge.

Norris, C., \& Armstrong, G. (1999a). CCTV and the social structuring of surveillance. In T. Nick \& P. Kate (Eds.), Surveillance of public space: CCTV, street lighting and crime prevention (Crime Prevention Studies, Vol. 10, pp. 157-178). Monsey: Criminal Justice Press.

Norris, C., \& Armstrong, G. (1999b). The maximum surveillance society. The rise of CCTV. Berg: Oxford.

Norris, C., \& McCahill, M. (2006). CCTV: beyond penal modernism? British Journal of Criminology, 46, 97118.

Olds, D. (2009). In support of disciplined passion. Journal of Experimental Criminology, 5(2), 201-214.

Olejnik, S., Li, J., Supattathum, S., \& Huberty, C. (1997). Multiple testing and statistical power with modified Bonferroni procedures. Journal of Education and Behavioral Statistics, 22, 389-406.

Pease, K. (1999). A review of street lighting evaluations: crime reduction effects. In N. Tilley \& K. Painter (Eds.), Surveillance of public space: CCTV, street lighting and crime prevention. Crime prevention studies (Vol. 10). Monsey: Criminal Justice Press.

Perneger, T. (1998). What's wrong with Bonferroni adjustments? British Medical Journal, 316(7139), 12361238.

Perneger, T. (1999). Multiple testing. British Medical Journal, 322, 226-231.

Piza, E. (2012). Identifying the ideal context for CCTV camera placement: an analysis of micro-level features. Doctoral Dissertation submitted to the Graduate School-Newark, Rutgers, The State University of New Jersey.

Piza, E., \& O'Hara, B. (2014). Saturation foot-patrol in a high-violence area: a quasi-experimental evaluation. Justice Quarterly, 31(4), 693-718.

Piza, E., Caplan, J., \& Kennedy, L. (2012). Is the punishment more certain? An analysis of CCTV detections and enforcement. Justice Quarterly. Advance online publication. doi:10.1080/07418825.2012.723034.

Piza, E., Caplan, J., \& Kennedy, L. (2014a). Analyzing the influence of micro-level factors on CCTV camera effect. Journal of Quantitative Criminology, 30(2), 237-264. 
Piza, E., Caplan, J., \& Kennedy, L. (2014b). CCTV as a tool for early police intervention: preliminary lessons from nine case studies. Security Journal. doi:10.1057/sj.2014.17.

Ratcliffe, J. (2006). Video surveillance of public places. Problem-oriented guides for police. Response guide series. Guide No. 4. U.S. Department of Justice Office of Community Oriented Policing Services. Center for Problem-Oriented Policing.

Ratcliffe, J., \& Breen, C. (2008). Spatial evaluation of police tactics in context (SEPTIC) spreadsheet, version 3 (spring 2010). Downloaded from www.jratcliffe.net.

Ratcliffe, J., Taniguchi, T., \& Taylor, R. (2009). The crime reduction effects of public CCTV cameras: a multimethod spatial approach. Justice Quarterly, 26(4), 746-770.

Ratcliffe, J., Taniguchi, T., Groff, E., \& Wood, J. (2011). The Philadelphia foot patrol experiment: a randomized controlled trial of police patrol effectiveness in violent crime hotspots. Criminology, 49(3), 795-831.

Reid, A., \& Andresen, M. (2014). An evaluation of CCTV in a car park using police and insurance data. Security Journal, 27, 57-79.

Sankoh, A., Huque, M., \& Dubey, S. (1997). Some comments on frequently used multiple endpoint adjustment methods in clinical trials. Statistics in Medicine, 16(22), 2529-3542.

Sarno, C., Hough, M., \& Bulos, M. (1999). Developing a picture of CCTV in Southwark Town Centres: final report. London: Criminal Policy Research Unit, South Bank University.

Sasse, M. (2010). Not seeing the crime for the cameras? Why it is difficult but essential to monitor the effectiveness of security technologies. Communications of the ACM, 53(2), 22-25.

Schulz, K. F., Altman, D. G., \& Moher, D. (2010). CONSORT 2010 statement: updated guidelines for reporting parallel group randomised trials. British Medical Journal, 340, 698-702.

Sherman, L. (1990). Police crackdowns: initial and residual deterrence. In M. Tonry \& N. Morris (Eds.), Crime and justice: a review of research (Vol. 12, pp. 1-48). Chicago: University of Chicago Press.

Sherman, L. (2010). An introduction to experimental criminology. In A. Piquero \& D. Weisburd (Eds.), Handbook of quantitative criminology (pp. 399-436). New York: Springer.

Sherman, L., \& Eck, J. (2002). Policing for crime prevention. In L. Sherman, D. Farrington, B. Welsh, \& D. MacKenzie (Eds.), Evidence-based crime prevention (pp. 295-329). New York: Routledge.

Sherman, L., Buerger, M., \& Gartin, P. (1989). Repeat call address policing: the Minneapolis RECAP experiment. Washington, DC: Crime Control Institute.

Skogan, W., \& Frydl, K. (eds) (2004). Fairness and effectiveness in policing: the evidence. Committee to Review Research on Police Policy and Practices. Committee on Law and Justice, Division of Behavioral and Social Sciences and Education. Washington, DC: The National Academies Press.

Smith, S., \& Bruce, C. (2008). CrimeStat III user workbook. Washington, DC: The National Institute of Justice.

Snijders, T. (2005). Power and sample size in multilevel linear models. In B. Everitt \& D. Howell (Eds.), Encyclopedia of statistics in behavioral science (Vol. 3, pp. 1570-1573). Chicester: Wiley.

Sorg, E., Haberman, C., Ratcliffe, J., \& Groff, E. (2013). Foot patrol in violent crime hot spots: the longitudinal impact of deterrence and posttreatment effects of displacement. Criminology, 51(1), 65-102.

Star Ledger, The (2010). Newark finalizes 167 police layoffs after union refuses Booker's plea to return to negotiating table. Tuesday, November 30th. Retrieved at: http://www.nj.com/news/index.ssf/2010/11/ union head expects 167 newark.html.

Taylor, E. (2010). Evaluating CCTV: why the findings are inconsistent, inconclusive and ultimately irrelevant. Crime Prevention and Community Safety: An International Journal, 12(4), 209-232.

Taylor, B., Koper, C., \& Woods, D. (2011). A randomized controlled trial of different policing strategies at hot spots of violent crime. Journal of Experimental Criminology, 7(2), 149-181.

Telep, C., Mitchell, R., \& Weisburd, D. (2012). How much time should the police spend at crime hot spots? Answers from a police agency directed randomized field trial in Sacramento, California. Justice Quarterly. Advance online publication. doi:10.1080/07418825.2012.710645.

Tilley, N. (1993). Understanding car parks, crime and CCTV. London: Crime Prevention Unit Series Paper 42 Home Office.

Tuttle, B. (2009). How Newark became Newark. Piscataway: Rutgers University Press.

U.S. Census Bureau (2010). State and county quick facts. Washington, DC: United States Census Bureau. http://quickfacts.census.gov. Accessed 9 Sept 2013.

Uitenbroek, D. (1997). SISA binomial. Southampton. http:/www.quantitativeskills.com/sisa/calculations/ bonfer.htm. Accessed 5 May 2014.

Waples, S., \& Gill, M. (2006). The effectiveness of redeployable CCTV. Crime Prevention and Community Safety, 8, 1-16. 
Warner, B., \& Pierce, G. (1993). Reexamining social disorganization theory using calls to the police as a measure of crime. Criminology, 31, 493-518.

Weisburd, D. (2008). Place-based policing (Ideas in Policing Series). Washington, DC: Police Foundation.

Weisburd, D., \& Eck, J. (2004). What can police do to reduce crime, disorder, and fear? Annals of the American Academy of Political and Social Science, 593, 42-65.

Weisburd, D., \& Gill, C. (2014). Block randomized trials at places: rethinking the limitations of small $\mathrm{n}$ experiments. Journal of Quantitative Criminology, 30(1), 97-112.

Weisburd, D., \& Green, L. (1995). Policing drug hot spots: the Jersey City drug market analysis experiment. Justice Quarterly, 12, 711-736.

Weisburd, D., Petrosino, A., \& Mason, G. (1993). Design sensitivity in criminal justice experiments. In T. Michael (Ed.), Crime and justice: an annual review of research (Vol. 17). Chicago: University of Chicago Press.

Weisburd, D., Wyckoff, L., Ready, J., Eck, J., Hinkle, J., \& Gajewski, F. (2006). Does crime just move around the corner? A controlled study of spatial displacement and diffusion of crime control benefits. Criminology, 44(3), 549-592.

Welsh, B., \& Farrington, D. (2002). Crime prevention effects of closed circuit television: a systematic review. London: Home Office (Research Study No. 25).

Welsh, B., \& Farrington, D. (2007). Closed-circuit television surveillance and crime prevention: a systematic review. Stockholm: National Council for Crime Prevention.

Welsh, B., \& Farrington, D. (2009). Public area CCTV and crime prevention: an updated systematic review and meta-analysis. Justice Quarterly, 26(4), 716-745.

Welsh, B., Braga, A., \& Hollis-Peel, M. (2012). Can "disciplined passion" overcome the cynical view? An empirical inquiry of evaluator influence on police crime prevention program outcomes. Journal of Experimental Criminology, 8(4), 415-431.

Wilson, O. W. (1963). Police administration. New York: McGraw-Hill.

Wyant, B., Taylor, R., Ratcliffe, J., \& Wood, J. (2012). Deterrence, firearm arrests, and subsequent shootings: a micro-level spatio-temporal analysis. Justice Quarterly, 29(4), 524-545.

Eric L. Piza is Assistant Professor at John Jay College of Criminal Justice, Department of Law and Police Science. He received his $\mathrm{PhD}$ from Rutgers University. His research interests include the spatial analysis of crime patterns, problem-oriented policing, crime control technology, and the integration of academic research and police practice.

Joel M. Caplan is Associate Professor at the Rutgers University School of Criminal Justice and Deputy Director of the Rutgers Center on Public Security. His research focuses on risk assessment, spatial analysis, and computational criminology, which takes the strengths of several disciplines and builds new methods and techniques for the analysis of crime and crime patterns.

Leslie W. Kennedy is University Professor in the Rutgers School of Criminal Justice and Director of the Rutgers Center on Public Security.

Andrew M. Gilchrist is a graduate student in the School of Criminal Justice at the University of Cincinnati. He research interests include the spatial concentration of crime and evidence-based policing strategies. 